\title{
Multi-Factor Modeling Method of the Load Sharing Ratio under Moving Train Loads
}

\author{
Yong Liu $\mathbb{D}^{1,2}$ Shiyu Zhang $\mathbb{D}^{1,{ }^{1,2,3}}$ Yang Jin $\mathbb{D}^{1,}{ }^{1,2}$ and Yuxiang Song $\mathbb{D}^{1,2}$ \\ ${ }^{1}$ School of Civil Engineering, Shijiazhuang Tiedao University, Shijiazhuang/050043, China \\ ${ }^{2}$ Key Laboratory of Roads and Railway Engineering Safety Control, Ministry of Education, Shijiazhuang Tiedao University, \\ Shijiazhuang/050043, China \\ ${ }^{3}$ School of Civil Engineering, Beijing Jiaotong University, Beijing/100044, China
}

Correspondence should be addressed to Shiyu Zhang; im.syzhang@outlook.com

Received 6 February 2021; Accepted 20 November 2021; Published 15 December 2021

Academic Editor: Nicolo Zampieri

Copyright (C) 2021 Yong Liu et al. This is an open access article distributed under the Creative Commons Attribution License, which permits unrestricted use, distribution, and reproduction in any medium, provided the original work is properly cited.

\begin{abstract}
In railway engineering, the load sharing ratio (LSR) is the ratio of the rail seat load (RSL) to the axle load, which is affected by many factors. The LSR can be used in the design and analysis of railway track structures as well as in the research of predicting the dynamic influence of railway tunnels and the environment. The "static loading method" commonly used to study the LSR does not conform to reality; using it, it is difficult to obtain a complete LSR curve, limiting its application. Besides, there is currently a lack of LSR prediction methods considering the impact of multiple factors. Therefore, this paper proposes a "moving loading method" for investigating the LSR under moving train excitation, verified to be rational by comparing with the experimental results. At the same time, a procedure for establishing the LSR multi-factor prediction model is put forward, namely, we (1) determine the LSR function form and the fitting algorithm; (2) perform parameter sensitivity analysis to determine the main influencing parameters of the LSR function; and (3) design a quadratic regression orthogonal test to obtain the prediction formula of the LSR function coefficients. Once establishing the prediction model for a type of train-track system, the LSR of similar systems can be calculated by adjusting the main parameters of the model. Shijiazhuang Metro Line 1 using the A-type vehicle and the monolithic trackbed is taken as a case study to develop a corresponding LSR multi-factor prediction model by the moving loading method and the procedure mentioned above. The results indicate that the proposed method performs well and can be adopted to enhance the accuracy of track design or tunnel and environmental vibration prediction.
\end{abstract}

\section{Introduction}

The rail seat load (RSL) is the load transferred from the rail to the underneath slabs via fastenings, rail seat plates, and sleepers. The load sharing ratio (LSR) is the ratio of the RSL to the axle load, reflecting the axle-load transmission law among wheelsets, rail, and fastenings. The maximum RSL, acting as the main parameter in the design and construction of railway tracks [1], needs to be calculated from the maximum axle load and the LSR. Moreover, recently increasing investigations have been devoted to reducing the model scale (for example, using 2.5D numerical methods) of the dynamic response prediction of railway tunnels [2] and the environment [3-7]. However, these models still include rail and fastenings, partly repeating with train-track coupling models. Omitting rail and fastenings and imposing the RSL time history calculated from the dynamic axle load and the LSR time history as the excitation can further simplify $2.5 \mathrm{D} \mathrm{nu}-$ merical models.

Current practices in the analysis and design of railway track systems assume the axle load to be static [8]. A dynamic coefficient is generally adopted worldwide to modify the axle load to reflect the effect of the load dynamic properties [9]. However, the current dynamic coefficient formulas recommended are different both in form and main parameters [10-19]. Early methods for determining LSR are also based on the static assumption using the static load or the dynamic modified static load, mainly including the three adjacent sleepers method $[11,14,20,21]$, Australian formula 
[22], AREA method [23], ORE method [24], Shinkansen method, and Chinese method [25]. Numerous studies have applied such approaches [9]; however, these methods are too rough to satisfy the requirement of railway track design [26] or environmental dynamic response prediction. Besides, there is also a lack of research on the matter of whether the static assumption is reasonable and how to determine the LSR time history function.

The LSR must be determined in light of the actual conditions because it is affected by many parameters of the train-track coupled dynamic system [9]. Jiang et al. [27, 28] developed a simple LSR formula based on the results of a high-speed railway model test, bringing a more accurate method for determining LSR than before. The only parameter in the function is the fastening stiffness; however, Zhou and Chen [29] hold that some other factors should not be ignored, such as the fastening spacing. Moreover, the wheelset is often located in any position between the adjacent fastenings during the train running, while all current studies merely focus on the point above one fastening or the middle point between two adjacent fastenings.

In this paper, a "moving loading method" is proposed to obtain the LSR under moving train excitation, verified to be reasonable by comparing with the literature [27]. At the same time, a procedure for establishing the LSR multi-factor prediction model is brought up. Using the method and the program, an LSR multi-factor prediction model is developed. The parameters in the model are determined according to Shijiazhuang Metro Line 1, in which the A-type vehicle and the monolithic trackbed are utilized. It is worth noting that establishing an accurate LSR multi-factor prediction model requires a lot of working conditions and data. Hence, the train-track coupled numerical model based on multi-body (MB) and finite element (FE) methods instead of model tests is used to acquire the main results in order to avoid considerable workload and high cost.

\section{Methodology for Obtaining the LSR under Moving Train Loads}

2.1. The LSR under the Excitation of a Single Wheel. Existing studies generally use the "static loading method," that is, applying a static load at a fixed position on the rail to calculate the LSR of surrounding fastening. When the axle load acts on a specific point, the load is distributed mainly by a total of six fastenings on both sides (five fastenings when the axle is directly above one fastening), as shown in Figure 1(a). This method is only useful when the wheel axle is located in a particular situation. Therefore, this article proposes a "moving loading method" as follows.

For a sure fastening, record the distance between the wheel axle and denote it as $D$. As shown in Figure 1(b), the LSR is not zero only when $D$ is less than $3 a$ ( $a$ is the distance between adjacent fastenings). When the train runs at a constant speed, for a specific train-rail system, the LSR of a single fastening is merely related to $D$. Regarding the metro track as a periodic structure, the LSR of each fastening varies with $D$ in the same way. Therefore, as shown in Figure 2, the LSR of a single fastening time history includes all the static loading method results, and the complete LSR curve is obtained only by transforming the $x$-axis from time to $D$.

2.2. The LSR under the Excitation of a Bogie. The "moving loading method" under a single wheel excitation regards the wheel as a point load and does not consider the real structure of the train and the complicated dynamic interaction between the wheel and the rail. The following assumptions are made to simplify the problem [28]: (1) when a single wheelset passes by, the LSR time-history curve is smooth and symmetrical; (2) in a certain train-track system, the LSR stimulated by each wheelset is exactly the same as the LSR stimulated by a single wheelset; and (3) all the LSR functions are superimposed assuming a linear superposition.

When loads from two wheels in a bogie are superimposed on a fastening, the corresponding M-shaped LSR time-history curve is shown in Figure 3(a). Due to the superposition of adjacent axle loads, the LSR curve of a single wheel is incomplete, but considering the symmetry, a complete curve can be obtained by half of the curve, as illustrated in Figure 3(b). The LSR under a whole train can be obtained by adding the LSR under the excitation of each wheel.

2.3. Verification. To investigate the effect of the moving loading method, a calculation is carried out using the static loading model test parameters of the literature [28], including the train speed $v=100 \mathrm{~km} / \mathrm{h}$, the fastening stiffness $k=28 \cdot 5 \mathrm{MN} / \mathrm{m}$, and the fastening spacing $a=0.63 \mathrm{~m}$. Figure 4 shows that the closer the fastener to the loading point, the greater the difference in LSR between the two curves. However, the maximum relative error between the two methods is about $18 \%$, and the maximum absolute error is merely $1.7 \%$, indicating that the results are very close. Both approaches suggest that the axle load is mainly borne by the surrounding five fastenings when the load is above the fastening and six when it is in the middle of two adjacent fastenings. Considering the negligible error between the two methods, the prediction model of the moving loading method can cover all the static loading method results.

\section{Methodology for Establishing an LSR Prediction Model}

A procedure for establishing the LSR multi-factor prediction model is put forward, which includes the following:

(1) Determination of the LSR function form and fitting algorithm.

(2) Parameter sensitivity analysis for determining the main parameters of the LSR function.

(3) Quadratic regression orthogonal tests for obtaining the prediction formula of the LSR function coefficients.

3.1. The LSR Function. The LSR curve is approximately a Gaussian curve [27]. Therefore, a Gaussian-like function is used to fit the LSR curve as follows: 


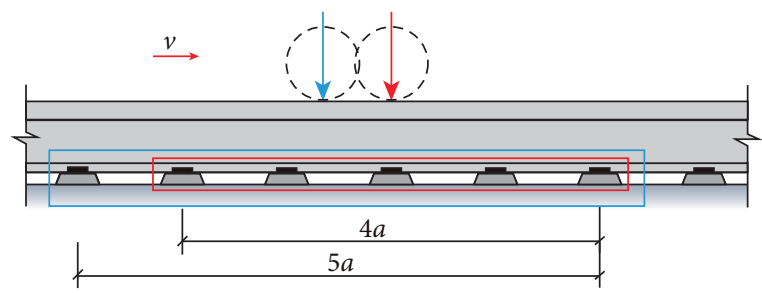

(a)

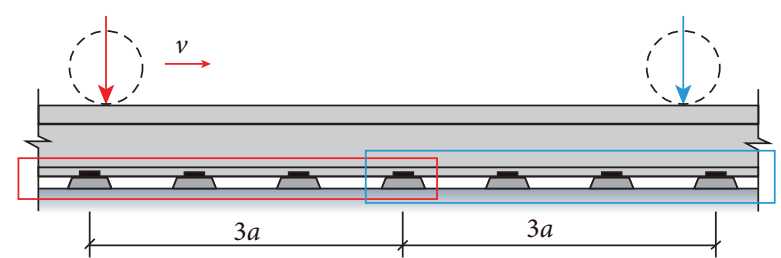

(b)

FIgURE 1: Fastening loads and LSR distribution under a single wheelset. (a) The distribution range of fastening loads under the static excitation. (b) The affected range of one fastening under the moving excitation.

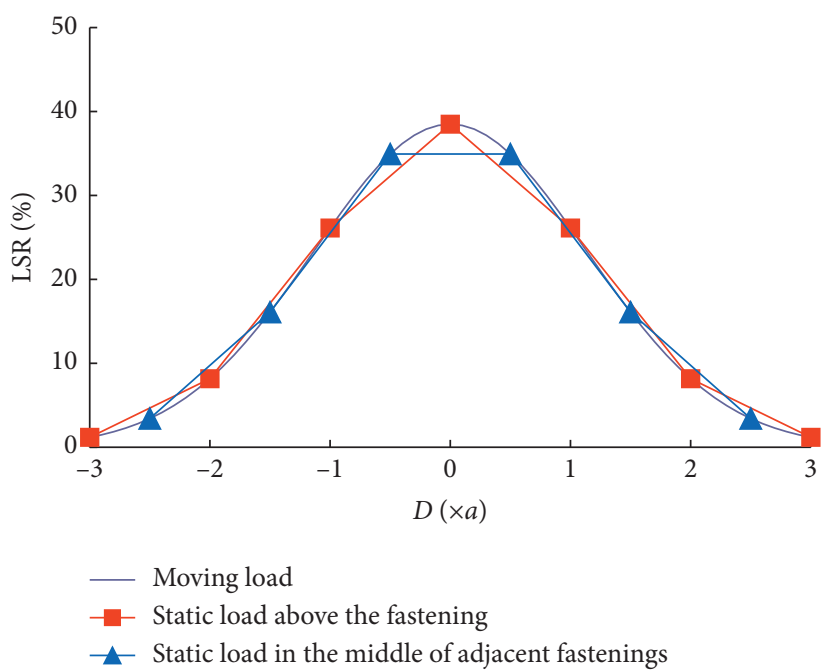

FIGURE 2: The LSR curves obtained by the moving loading method and static loading method.

$$
\gamma(x)=e^{\left(A-B x^{2}\right)} \times 1 \%
$$

where $\gamma(x)$ is the LSR; $x$ is the ratio of $D$ to $a$ ( $a$ is fastening spacing); and $A$ and $B$ are constants determined by actual conditions. The Levenberg-Marquardt optimization algorithm is used for fitting.

3.2. Parameter Sensitivity Analysis. The LSR is affected by many factors, including train speed, axle load, fastening stiffness, fastening damping, fastening spacing, trackbed elastic modulus, and subsoil stiffness [30]. To achieve quantitative analysis, a parameter sensitivity analysis method is employed to find the main parameters. The parameter sensitivity in the form of the ratio of the objective function to the relative change rate of the influencing parameter is adopted as follows:

$$
S_{i j}^{\gamma}=\frac{\Delta \gamma_{i} / \gamma_{i}^{0}}{\Delta x_{j} / x_{j}^{0}},
$$

where $S_{i j}^{\gamma}$ is the sensitivity of the LSR $\gamma_{i}$ to the $j$ th parameter $x_{j}$ at the $i$ th position of the load; $\Delta x_{j}$ is the parameter variation; $\Delta \gamma_{i}$ is the LSR variation with parameter $x_{j} ; \gamma_{i}^{0}$ is the initial value of the LSR at the $i$ th position; $x_{j}^{0}$ is the initial value of the $j$ th parameter $x_{j} ; i=1,2, \ldots, n$; $j=1,2, \ldots, m$; and $n$ and $m$ are the maximum numbers of positions and parameters, respectively.

The LSR function sensitivity to different parameters is still a function related to variable $D$, bringing difficulties in selecting the main parameters. Regarding the coefficients $A$ and $B$ as target parameters, equation (2) is transformed into the following form:

$$
\begin{gathered}
S_{j}^{A}=\frac{\Delta A_{j} / A_{0}}{\Delta x_{j} / x_{j}^{0}}, \\
S_{j}^{B}=\frac{\Delta B_{j} / B_{0}}{\Delta x_{j} / x_{j}^{0}},
\end{gathered}
$$

where $S_{j}^{A}$ and $S_{j}^{B}$ are separately the sensitivity factors of $A$ and $B$ to the $j$ th parameter $x_{j} ; \Delta A_{j}$ and $\Delta B_{j}$ are separately the variations of $A$ and $B$ with $x_{j}$; and $A_{0}$ and $B_{0}$ are individually the initial values of $A$ and $B$.

3.3. Determining the Coefficient Formulas. To generalize equation (1) into a universal empirical formula, it is necessary to further explore the valuing method for $A$ and $B$. After determining the main parameters of the LSR function, a quadratic regression orthogonal test is designed, and the 


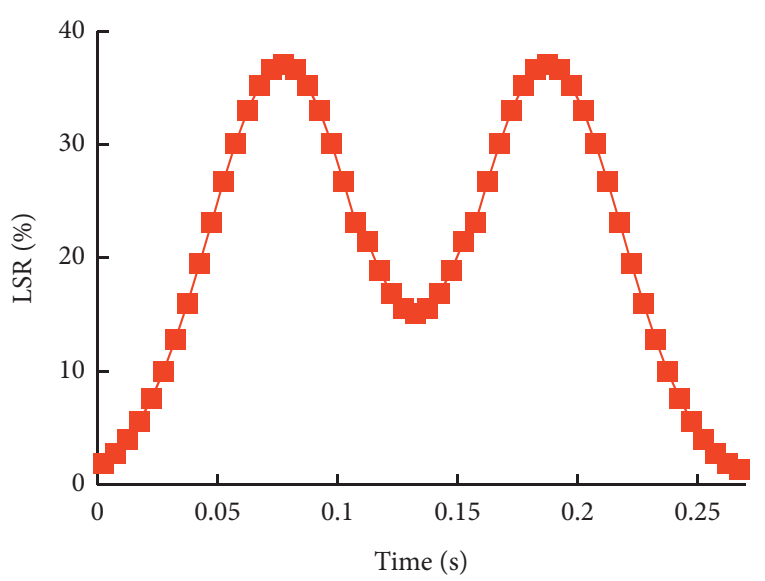

(a)

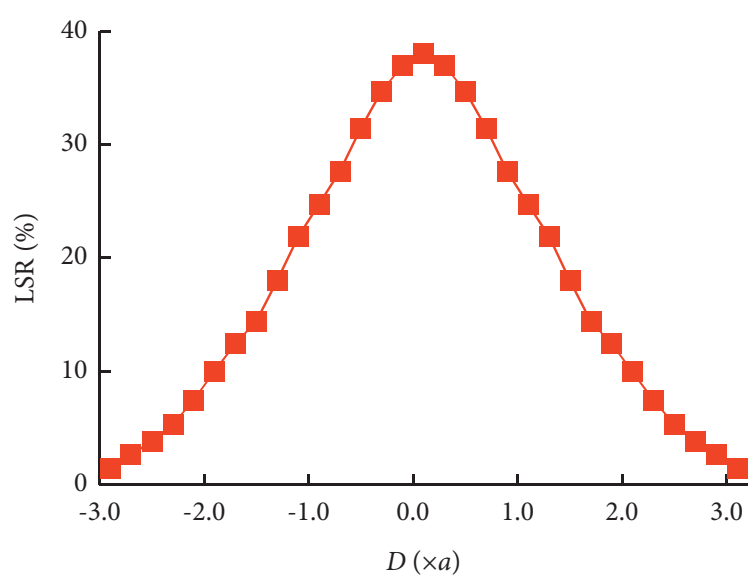

(b)

FIgURE 3: LSR curves under a bogie and a wheelset, respectively. (a) LSR curve under the excitation of a bogie. (b) LSR curve under the excitation of a wheel.

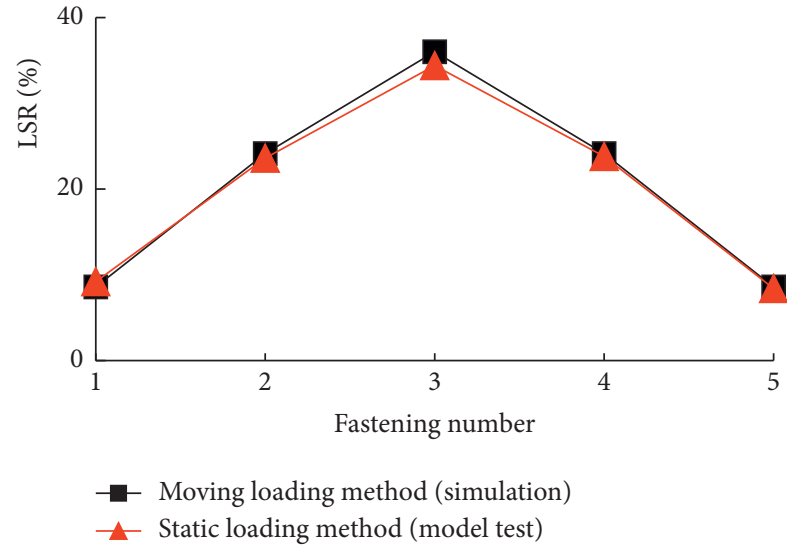

(a)

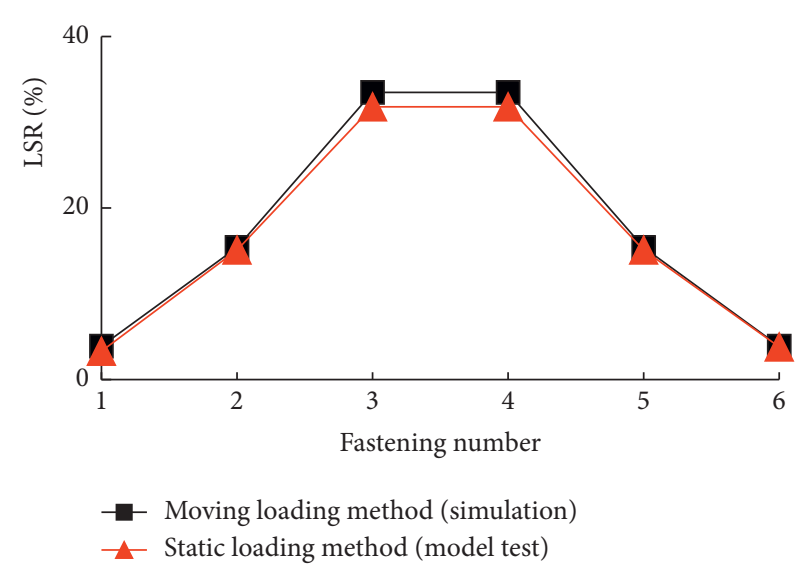

(b)

FIGURE 4: Comparison of the LSR results obtained by the two methods. (a) LSR curves when the load is located above the fastening. (b) LSR curves when the load is located in the middle of adjacent fastenings.

value functions of $A$ and $B$ under multiple parameters are established, respectively. To simplify the treatment process of data, the actual value of each test factor $x_{j}$ is firstly linearly transformed into the factor level code $z_{j}$ as follows:

$$
\begin{gathered}
z_{j}=\frac{\left(x_{j}-x_{0 j}\right)}{\Delta_{j}}, \\
\Delta_{j}=\frac{\left(x_{2 j}-x_{0 j}\right)}{\gamma},
\end{gathered}
$$

where $x_{0 j}$ is the average of the upper and lower bounds of the $i$ th experimental factor $x_{j} ; x_{2 j}$ is the upper bound of $x_{j} ; \Delta_{j}$ is the variation range of $x_{j}$; and $\gamma$ is the asterisk arm which can be calculated as follows:

$$
\gamma=\sqrt{\frac{\sqrt{\left(m_{c}+2 m+m_{0}\right) m_{c}-m_{c}}}{2}},
$$

where $m$ is the number of test factors; $m_{0}$ is the number of zero-level tests; and $m_{c}$ is the number of two-level trials.

Quadratic regression orthogonal analysis needs to consider the influence of a single factor $z_{j}$ and the impact between two factors $z_{k} z_{j}$; hence, the quadratic regression equations of parameters $A$ and $B$ are shown as follows:

$$
\begin{gathered}
\widehat{A}=a_{0}+\sum_{j=1}^{n} a_{j} z_{j}+\sum_{j=1}^{n} \sum_{k=1}^{n-1} a_{k j} z_{k} z_{j}+\sum_{j=1}^{n} a_{j j} z_{j}^{2}, \\
\widehat{B}=b_{0}+\sum_{j=1}^{n} b_{j} z_{j}+\sum_{j=1}^{n} \sum_{k=1}^{n-1} b_{k j} z_{k} z_{j}+\sum_{j=1}^{n} b_{j j} z_{j}^{2},
\end{gathered}
$$


where $\widehat{A}$ and $\widehat{B}$ are the estimated values of parameters $A$ and $B$; $n$ is the number of test factors; and $a_{0}, a_{j}, a_{k j}, a_{j j}, b_{0}, b_{j}$, $b_{k j}$, and $b_{j j}$ are all regression coefficients.

\section{Case Study}

The concrete monolithic trackbed has the characteristics of good integrity and high rigidity and is a commonly used track form in metro underground lines [31]. Shijiazhuang Metro Line 1 using the A-type train and the monolithic trackbed was taken as an example. The LSR data were obtained employing a numerical model based on the moving loading method, and a multi-factor prediction model of LSR was developed.

4.1. Numerical Model. The instance is an A-type metro train with six cars including four motor cars and two trailer cars. The train size is shown in Figure 5, and the main parameters are shown in Table 1. Each vehicle subsystem had several rigid bodies including one carbody, two frames, four wheelsets, and eight axle boxes, and each body had six degrees of freedom in the longitudinal, lateral (transverse), vertical (up and down), side roll, pitch, and yaw. Therefore, each vehicle subsystem had 90 degrees of freedom. The train model established by the MB software named Universal Mechanism (UM) is shown in Figure 6(a). The axle load of the fully loaded train was about $14.8 \mathrm{t}$, and the vehicle runs at a constant speed of $80 \mathrm{~km} / \mathrm{h}$.

The rails were modeled as Timoshenko beams, and the fastenings were modeled as a series of spring-damper pairs [32] with a fastening spacing of $a=0.6 \mathrm{~m}$. The monolithic trackbed and the circular cross section tunnel lining were modeled as a whole FE system without creating separate sleeper models. The geometry and properties of the tracktunnel-soil system are separately shown in Figure 7(a) and Table 2. Based on the linear viscoelastic constitutive model, a FE model of the trackbed-tunnel bottom was established using the element type of SOLID 45 in the software ANSYS, as shown in Figure 7(b). The longitudinal length of the model was $120 \mathrm{~m}$, and the element size was $0.11-0.3 \mathrm{~m}$. The Craig-Bampton method was adopted to couple the FE model and the MB model in the software UM. Springdamper pairs were used to simulate the subsoil, whose stiffness and damping coefficients were determined separately according to the literatures $[33,34]$.

There are many wheel-rail interaction models. In this paper, the Kik-Piotrowski multi-point contact algorithm [35] was used to simulate the contact between wheels and rail. Figure 7(b) shows the train-track coupling model.

Track irregularity is the main reason for the dynamic excitation of trains [36]. The environmental vibration response caused by the metro operation is mainly vertical [37]. Hence, it is generally considered that the vertical wheel-rail force is the primary excitation source, so only vertical track irregularities were considered [38]. At present, the American Class 6 track irregularity spectrum and the Sato track irregularity spectrum are commonly used to simulate medium and long wave and short wave irregularities in metro tracks,

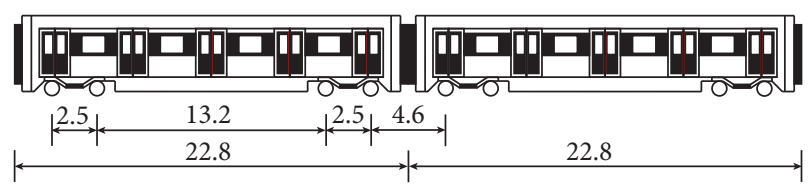

Figure 5: Train size (m).

respectively [36]. However, some studies have shown that the American Class 6 track irregularity spectrum differs significantly from the actual metro track irregularities [39-41]. This research used the Shanghai Metro track spectrum [39] and Sato track irregularity spectrum [42] to simulate vertical track irregularities. Figure 8 shows the sample data.

4.2. Results. $S_{j}^{A}$ and $S_{j}^{B}$ obtained from equation (3) do not change with $D$, facilitating an intuitive comparison of the influence of various parameters. The reference values of parameters were determined according to the actual situation of Shijiazhuang Metro Line 1, and the change rate of each parameter took the same small amount (10\%). The calculation conditions are shown in Table 3 , where condition 3 increases the mass of each rigid body in the train model by $10 \%$. In fact, the mass of carbody, bogie, and wheelset has different influence on LSR, but here the vehicle is taken as a whole, and only the influence of total vehicle mass on LSR is considered to reduce the number of influencing factors. In the process of changing the mass of each body, the change of vehicle structure is not expected. Therefore, assuming that the influence of mass change as small as $10 \%$ on vehicle structural characteristics can be ignored, the mass of each rigid body is increased by $10 \%$.

According to the conditions in Table 3, the vehicle-rail coupling calculation is performed to obtain the corresponding LSR data. The calculated discrete data cannot fully reflect the LSR when the wheel is at any position, so the Levenberg-Marquardt optimization algorithm was used to fit each data group according to equation (1) (see Figure 9).

Figures 10(a) and 10(b) show the sensitivity curves of LSR and the coefficients $A$ and $B$ to each parameter calculated by equations (2) and (3) individually. As shown in Figure 10(a), factors have different effects on the LSR of different locations, resulting in different parameter sensitivity distribution laws. Besides, the impact of axle load varies with $D$ in the opposite trend with other factors. Figure 10(b) implies that the coefficients $A$ and $B$ have considerable absolute values of the parameter sensitivity of the fastening stiffness and the fastening spacing, so they were regarded as the main influencing parameters.

The fastening stiffness change range was taken to be $20-50 \mathrm{MN} \mathrm{m}^{-1}$, and the fastening spacing change range was assumed to be $0.5-0.65 \mathrm{~m}$. A two-factor quadratic regression orthogonal test was designed, and the factor level coding is shown in Table 4 . The number of test factors was $m=2$, and the length of the asterisk arm was $\gamma=1.078$. The number of two-level tests was $m_{c}=2^{m}=4$; the number of asterisks was $m_{\gamma}=2 m=4$; and the number of zero-level tests was $m_{0}=2$. Therefore, the total number of test groups was $N=10$. 
TABLE 1: Key parameters of the vehicle model.

\begin{tabular}{|c|c|c|c|c|}
\hline Location & Notation & Item & Value & Unit \\
\hline Carbody & $\begin{array}{l}M_{c} \\
I_{c x x} \\
I_{c y y} \\
I_{c z z}\end{array}$ & $\begin{array}{l}\text { Mass of fully loaded carbody } \\
\text { Side roll inertia moment of carbody } \\
\text { Pitch inertia moment of carbody } \\
\text { Yaw inertia moment of carbody }\end{array}$ & $\begin{array}{l}4.81 \times 10^{4} \\
4.38 \times 10^{4} \\
8.88 \times 10^{5} \\
8.76 \times 10^{5}\end{array}$ & $\begin{array}{l}\mathrm{kg} \\
\mathrm{kg} \cdot \mathrm{m}^{2} \\
\mathrm{~kg} \cdot \mathrm{m}^{2} \\
\mathrm{~kg} \cdot \mathrm{m}^{2}\end{array}$ \\
\hline Frame & $\begin{array}{l}M_{f} \\
I_{f x x} \\
I_{f y y} \\
I_{f z z}\end{array}$ & $\begin{array}{c}\text { Mass of frame } \\
\text { Side roll inertia moment of frame } \\
\text { Pitch inertia moment of frame } \\
\text { Yaw inertia moment of frame }\end{array}$ & $\begin{array}{l}1.65 \times 10^{3} \\
1.09 \times 10^{3} \\
1.78 \times 10^{3} \\
248 \\
\end{array}$ & $\begin{array}{r}\mathrm{kg} \\
\mathrm{kg} \cdot \mathrm{m}^{2} \\
\mathrm{~kg} \cdot \mathrm{m}^{2} \\
\mathrm{~kg} \cdot \mathrm{m}^{2}\end{array}$ \\
\hline Wheelsets & $\begin{array}{l}M_{w} \\
I_{w x x} \\
I_{w y y} \\
I_{w z z}\end{array}$ & $\begin{array}{c}\text { Mass of wheelset } \\
\text { Side roll inertia moment of wheelset } \\
\text { Pitch inertia moment of wheelset } \\
\text { Yaw inertia moment of wheelset }\end{array}$ & $\begin{array}{l}1.78 \times 10^{3} \\
1.05 \times 10^{3} \\
129 \\
1.05 \times 10^{3}\end{array}$ & $\begin{array}{c}\mathrm{kg} \\
\mathrm{kg} \cdot \mathrm{m}^{2} \\
\mathrm{~kg} \cdot \mathrm{m}^{2} \\
\mathrm{~kg} \cdot \mathrm{m}^{2}\end{array}$ \\
\hline Axle box & $\begin{array}{l}M_{\mathrm{b}} \\
I_{b x x} \\
I_{b y y} \\
I_{b z z}\end{array}$ & $\begin{array}{c}\text { Mass of axle box } \\
\text { Side roll inertia moment of axle box } \\
\text { Pitch inertia moment of axle box } \\
\text { Yaw inertia moment of axle box }\end{array}$ & $\begin{array}{c}84 \\
1 \\
3.9 \\
3.38 \\
\end{array}$ & $\begin{array}{c}\mathrm{kg} \\
\mathrm{kg} \cdot \mathrm{m}^{2} \\
\mathrm{~kg} \cdot \mathrm{m}^{2} \\
\mathrm{~kg} \cdot \mathrm{m}^{2}\end{array}$ \\
\hline Suspension & $\begin{array}{l}k_{1} \\
c_{1} \\
k_{2} \\
c_{2}\end{array}$ & $\begin{array}{l}\text { Vertical stiffness of primary suspension } \\
\text { Vertical damping of primary suspension } \\
\text { Vertical stiffness of secondary suspension } \\
\text { Vertical damping of secondary suspension }\end{array}$ & $\begin{array}{l}7.50 \times 10^{5} \\
2.00 \times 10^{4} \\
2.04 \times 10^{5} \\
3.00 \times 10^{4}\end{array}$ & $\begin{array}{l}\mathrm{N} / \mathrm{m} \\
\mathrm{N} \cdot \mathrm{s} / \mathrm{m} \\
\mathrm{N} / \mathrm{m} \\
\mathrm{N} \cdot \mathrm{s} / \mathrm{m}\end{array}$ \\
\hline
\end{tabular}

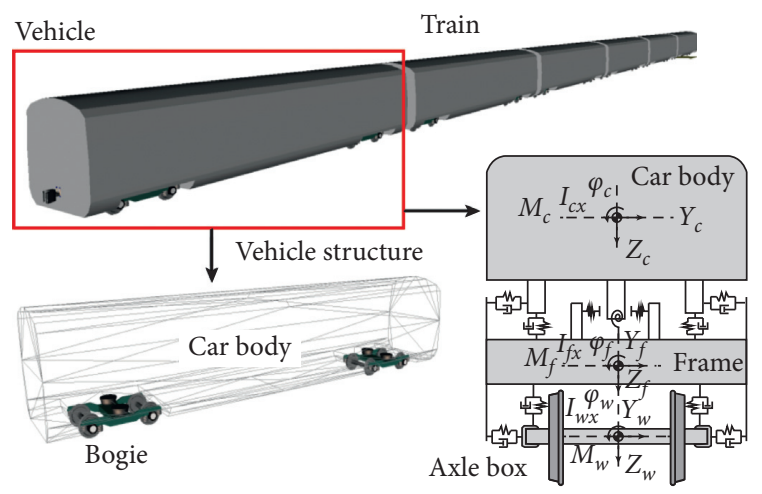

Wheelset

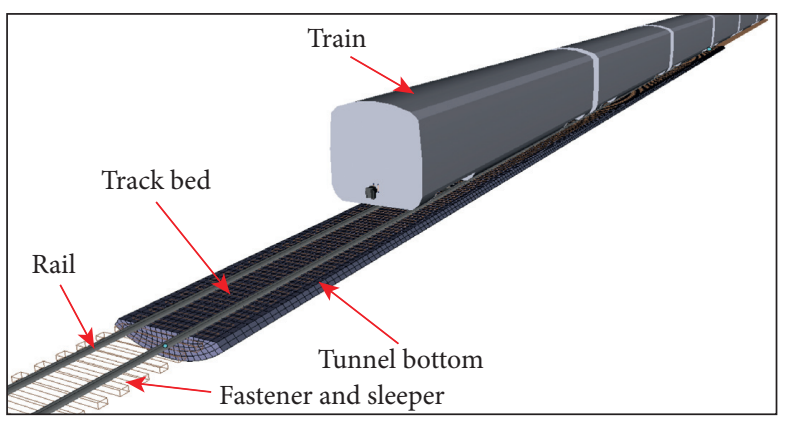

(b)

Figure 6: Train model and train-track coupling model. (a) Multi-rigid body train model. (b) Train-track coupling model.

(a)

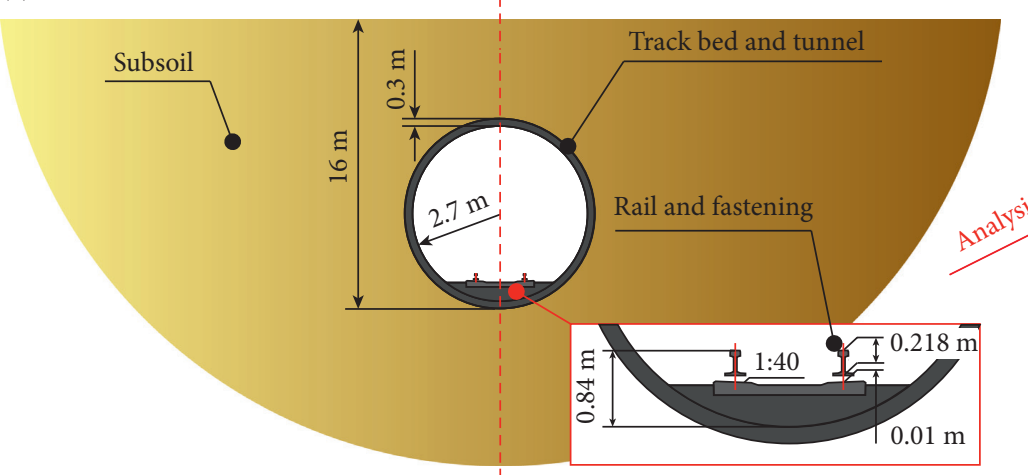

(b)

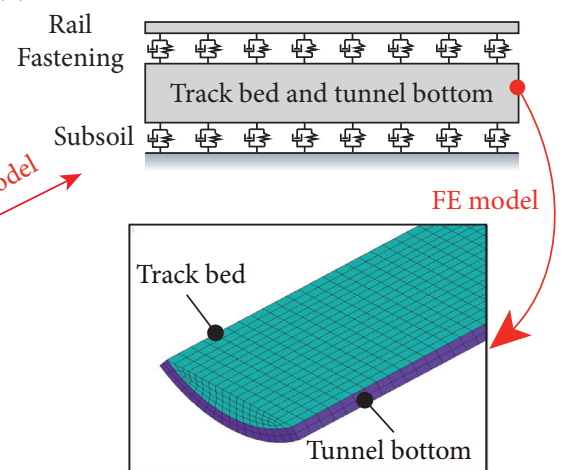

FIGURE 7: Geometry and the simplified model adopted for modeling the track-tunnel-soil system. (a) Geometry of the track-tunnel-soil system. (b) The simplified model of the track-tunnel-soil system. 
TABLe 2: Properties of the track-tunnel-soil system.

\begin{tabular}{|c|c|c|c|c|}
\hline Location & Notation & Item & Value & Unit \\
\hline \multirow{7}{*}{ Track and tunnel } & $m_{r}$ & Mass per meter of rail & 60.64 & $\mathrm{~kg} / \mathrm{m}$ \\
\hline & $k_{f}$ & Vertical stiffness of fastening & $4.07 \times 10^{7}$ & $\mathrm{~N} / \mathrm{m}$ \\
\hline & $c_{f}$ & Vertical damping of fastening & $9.90 \times 10^{3}$ & $\mathrm{~N} \cdot \mathrm{s} / \mathrm{m}$ \\
\hline & $\rho_{t}$ & Density of trackbed and tunnel & $2.50 \times 10^{3}$ & $\mathrm{~kg} / \mathrm{m}^{3}$ \\
\hline & $E_{t}$ & Young's modulus of trackbed and tunnel & $3.55 \times 10^{10}$ & $\mathrm{~Pa}$ \\
\hline & $\mu_{t}$ & Poison ratio of trackbed and tunnel & 0.25 & - \\
\hline & $\zeta_{t}$ & Damping ratio of trackbed and tunnel & 0.05 & - \\
\hline \multirow{4}{*}{ Soil } & $E_{s}$ & Young's modulus of soil & $3.50 \times 10^{8}$ & $\mathrm{~Pa}$ \\
\hline & $\mu_{s}$ & Poisson's ratio of soil & 0.34 & - \\
\hline & $C_{s}$ & Shear wave velocity of soil & 208 & $\mathrm{~m} / \mathrm{s}$ \\
\hline & $C_{p}$ & Compression shear wave velocity of soil & 331 & $\mathrm{~m} / \mathrm{s}$ \\
\hline
\end{tabular}

(a)

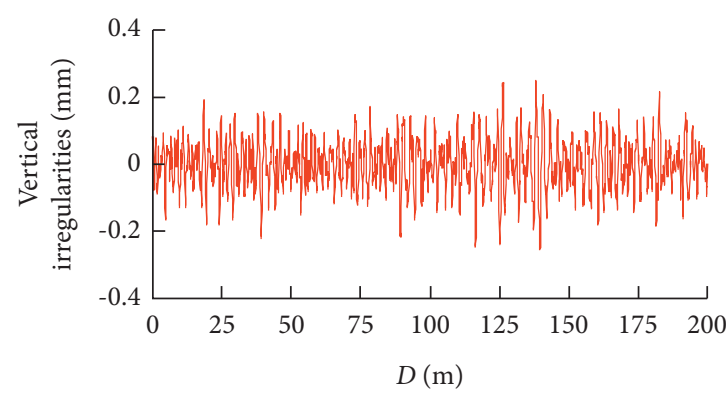

(c)

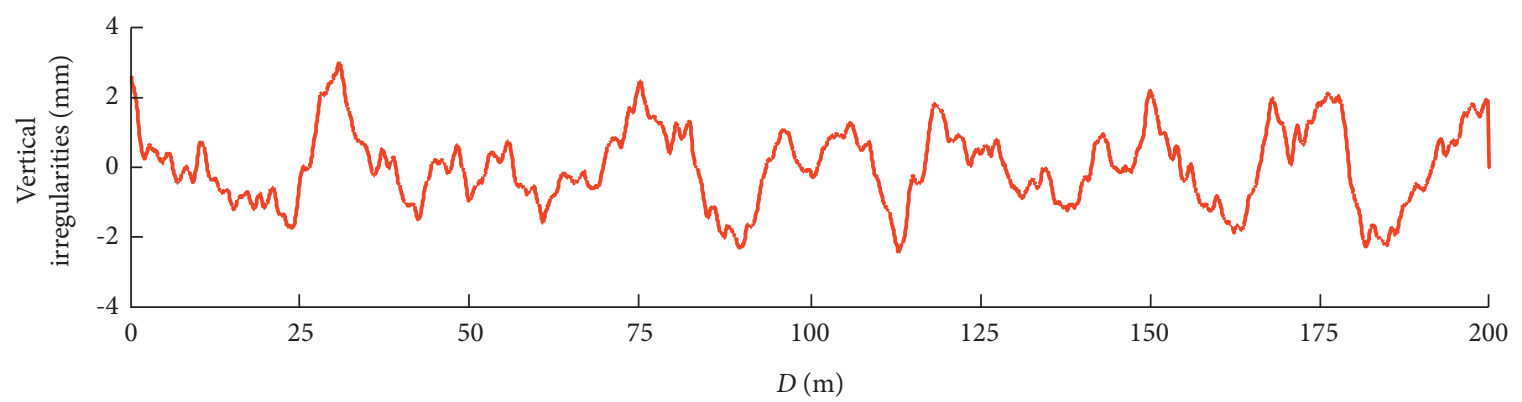

Figure 8: Sample data of vertical track irregularities. (a) Short wave irregularities. (b) Medium and long wave irregularities. (c) Superimposed wave irregularities.

TABLE 3: Parameter sensitivity analysis conditions.

\begin{tabular}{lccccccc}
\hline Condition & $v\left(\mathrm{~km} \cdot \mathrm{h}^{-1}\right)$ & $m_{a}(t)$ & $k_{f}\left(\mathrm{MN} \cdot \mathrm{m}^{-1}\right)$ & $c_{f}\left(\mathrm{kN} \cdot \mathrm{s} \cdot \mathrm{m}^{-1}\right)$ & $a(\mathrm{~m})$ & $E_{t}(\mathrm{MPa})$ & $k_{s}\left(\mathrm{MN} \cdot \mathrm{m}^{-1}\right)$ \\
\hline 1 & 80 & 14.80 & 40.73 & 9.90 & 0.60 & 35500 & 862.11 \\
2 & 88 & 14.80 & 40.73 & 9.90 & 0.60 & 35500 & 862.11 \\
3 & 80 & 16.28 & 40.73 & 9.90 & 0.60 & 35500 & 862.11 \\
4 & 80 & 14.80 & 44.80 & 9.90 & 0.60 & 35500 & 862.11 \\
5 & 80 & 14.80 & 40.73 & 10.89 & 0.60 & 35500 & 862.11 \\
6 & 80 & 14.80 & 40.73 & 9.90 & 0.66 & 35500 & 862.11 \\
7 & 80 & 14.80 & 40.73 & 9.90 & 0.60 & 39050 & 862.11 \\
8 & 80 & 14.80 & 40.73 & 9.90 & 0.60 & 35500 & 948.32 \\
\hline
\end{tabular}

$\nu$ is the train speed; $m_{\mathrm{a}}$ is the axle load; $k_{f}$ is the fastening stiffness; $c_{f}$ is the fastening damping; $a$ is the fastening spacing; $E_{b}$ is the trackbed elastic modulus; and $k_{s}$ is the subsoil stiffness, that is, the stiffness of the equivalent spring of subsoil. 


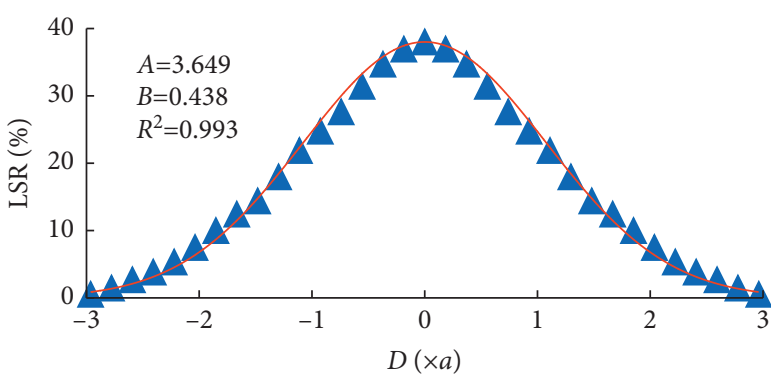

A Simulation result

__ Fitting curve 1

(a)

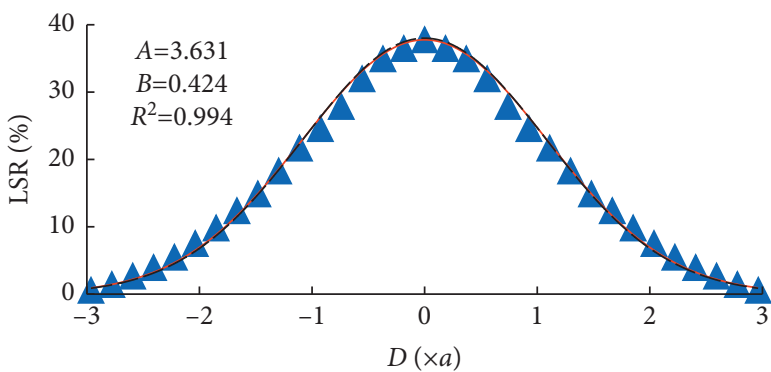

A Simulation result

- Fitting curve 3

- - - Fitting curve 1

(c)

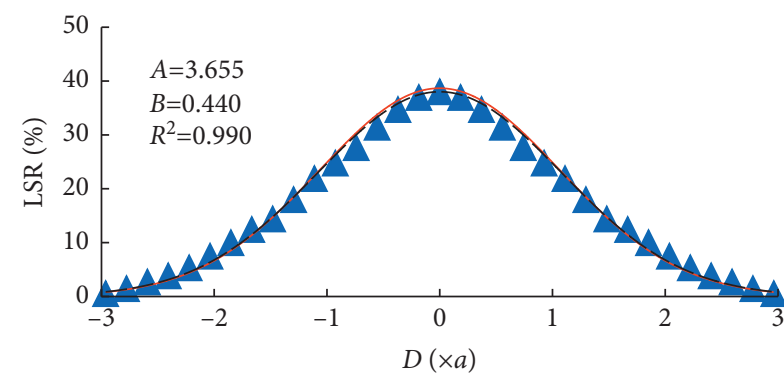

- Simulation result

— Fitting curve 5

- - - Fitting curve 1

(e)

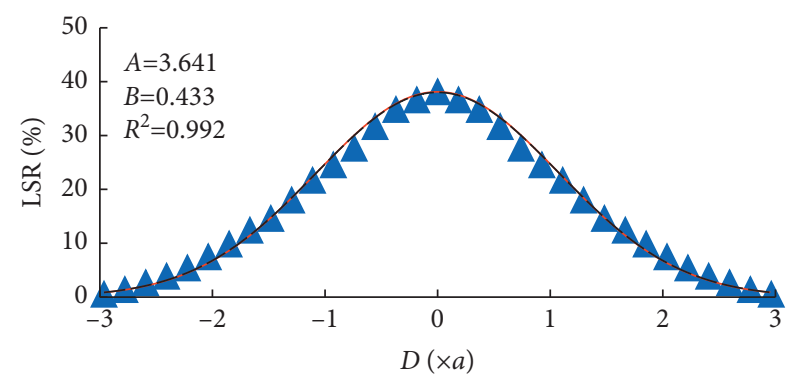

- Simulation result

- Fitting curve 7

- - - Fitting curve 1

(g)

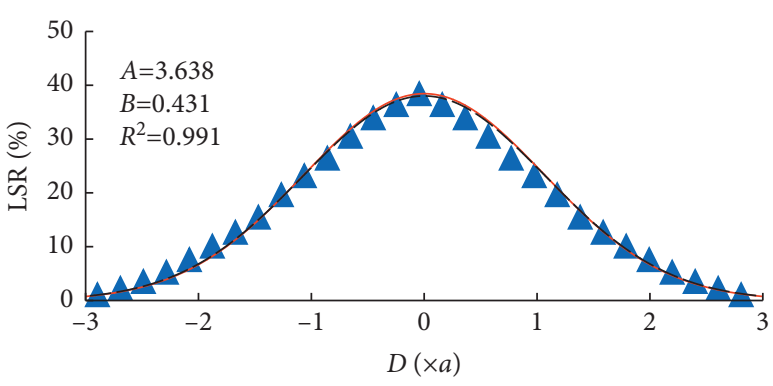

A Simulation result

__ Fitting curve 2

- - - Fitting curve 1

(b)

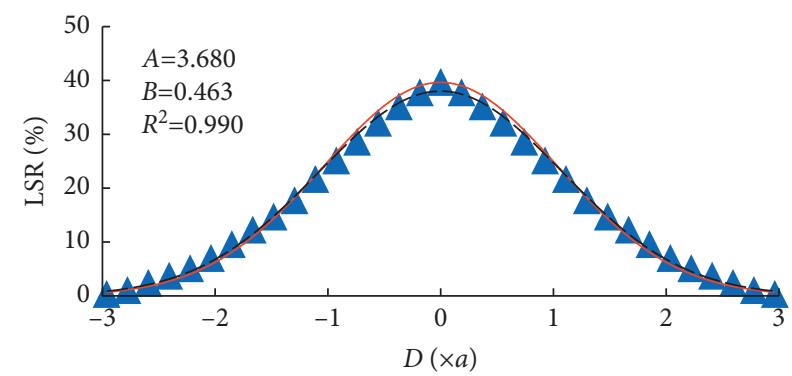

A Simulation result

- Fitting curve 4

- - - Fitting curve 1

(d)

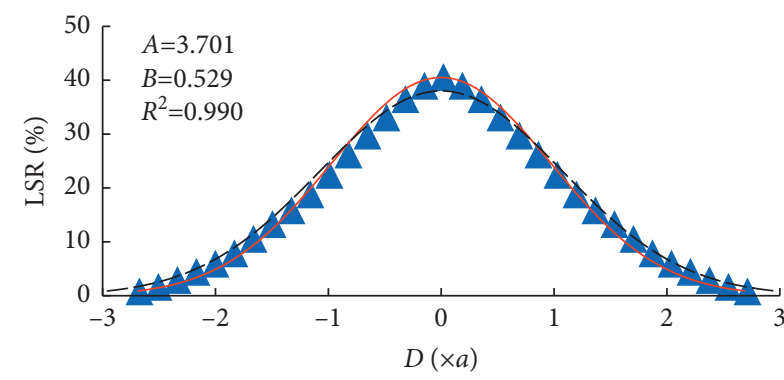

A Simulation result

_ Fitting curve 6

- - - Fitting curve 1

(f)

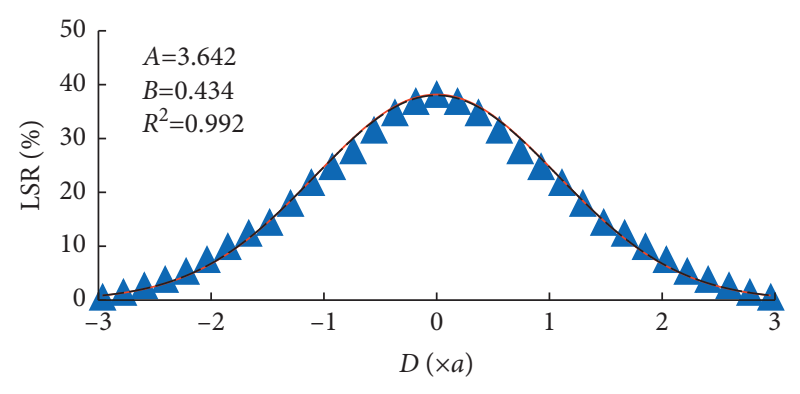

A Simulation result

- Fitting curve 8

- - - Fitting curve 1

FIgURE 9: The fitting curves of the LSRs under different conditions. (a) Condition 1 (initial). (b) Condition 2 ( $v$ is modified). (c) Condition 3 ( $m_{a}$ is modified). (d) Condition $4\left(k_{f}\right.$ is modified). (e) Condition 5 ( $c_{f}$ is modified). (f) Condition 6 ( $a$ is modified). (g) Condition 7 ( $E_{b}$ is modified). (h) Condition 8 ( $k_{s}$ is modified). The values of coefficients $A$ and $B$ are shown in the figure, and $R^{2}$ is the goodness of fit. 


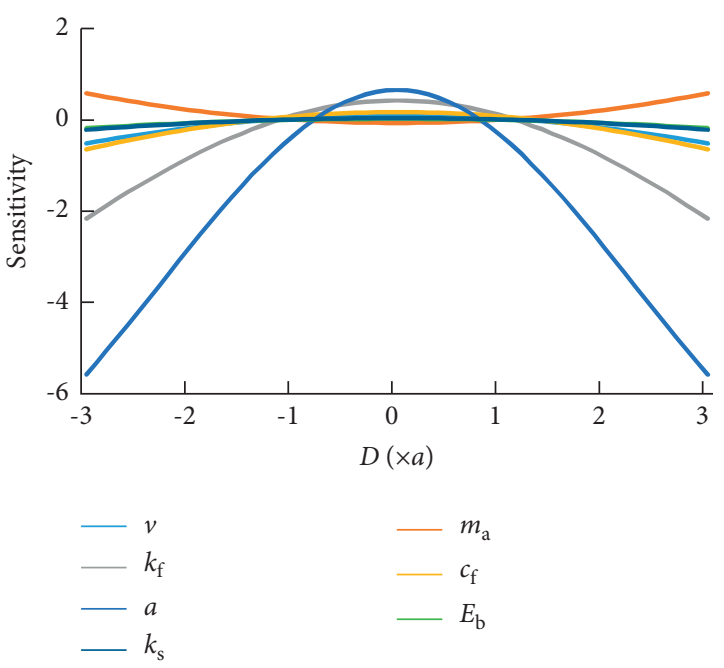

(a)

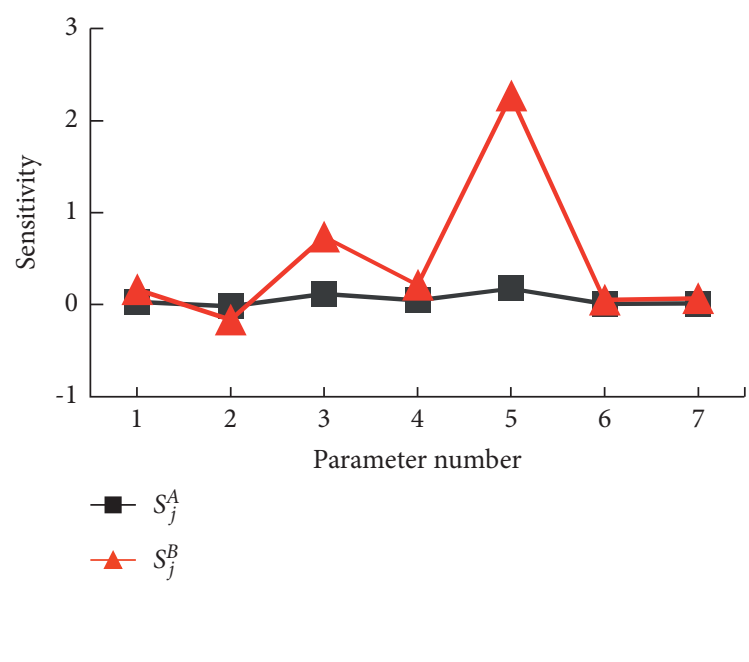

(b)

FIgURe 10: Parameter sensitivity curves. (a) Parameter sensitivity curves of LSR. (b) Parameter sensitivity curves of coefficients $A$ and $B$.

TABLE 4: Factor level coding.

\begin{tabular}{|c|c|c|c|c|c|c|}
\hline Test factor level & Zero level (0) & Variation range $(\Delta)$ & Upper level $(+1)$ & Lower level $(-1)$ & Upper asterisk arm $(+1.078)$ & $\begin{array}{c}\text { Lower asterisk } \\
\text { arm } \\
(-1.078)\end{array}$ \\
\hline$\overline{k_{f}\left(\mathrm{MN} \cdot \mathrm{m}^{-1}\right)}$ & 35 & 13.91 & 48.91 & 21.09 & 50 & 20 \\
\hline$a(\mathrm{~m})$ & 0.575 & 0.07 & 0.64 & 0.51 & 0.65 & 0.5 \\
\hline
\end{tabular}

TABLE 5: Test factor levels and calculation results.

\begin{tabular}{lccccccc}
\hline Test number & $z_{1}$ & $z_{2}$ & $z_{1} \cdot z_{2}$ & $z_{1}{ }^{2}$ & $z_{2}{ }^{2}$ & $A$ & $R^{2}$ \\
\hline 1 & 1 & 1 & 1 & 1 & 1 & 3.716 & 0.486 \\
2 & 1 & -1 & -1 & 1 & 1 & 3.573 & 0.422 \\
3 & -1 & 1 & -1 & 1 & 1 & 3.762 & 0.535 \\
4 & -1 & -1 & 1 & 1 & 1 & 3.324 & 0.295 \\
5 & 1.078 & 0 & 0 & 1.162 & 0 & 3.671 & 0.438 \\
6 & -1.078 & 0 & 0 & 1.162 & 0 & 3.436 & 0.288 \\
7 & 0 & 1.078 & 0 & 0 & 1.162 & 3.641 & 0.958 \\
8 & 0 & -1.078 & 0 & 0 & 1.162 & 3.456 & 0.992 \\
9 & 0 & 0 & 0 & 0 & 0 & 3.553 & 0.987 \\
10 & 0 & 0 & 0 & 0 & 0 & 3.562 & 0.357 \\
\end{tabular}

Table 5 shows the values of test factor levels and the corresponding coefficients of fitting functions.
By carrying out regression analysis according to the orthogonal experiment results, the regression equations were obtained as follows:

$$
\begin{gathered}
\widehat{A}=3 \cdot 544+0 \cdot 072 z_{1}+0 \cdot 124 z_{2}-0 \cdot 074 z_{1} z_{2}+0 \cdot 023 z_{1}^{2}+0 \cdot 018 z_{2}^{2}, R^{2}=0 \cdot 928 \\
\widehat{B}=0 \cdot 339+0 \cdot 038 z_{1}+0 \cdot 061 z_{2}-0 \cdot 044 z_{1} z_{2}+0 \cdot 036 z_{1}^{2}+0 \cdot 049 z_{2}^{2}, R^{2}=0 \cdot 863
\end{gathered}
$$




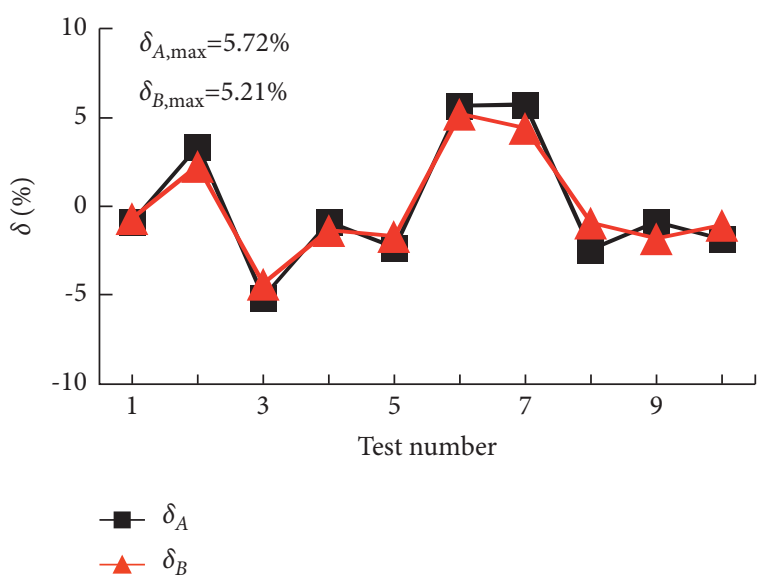

(a)

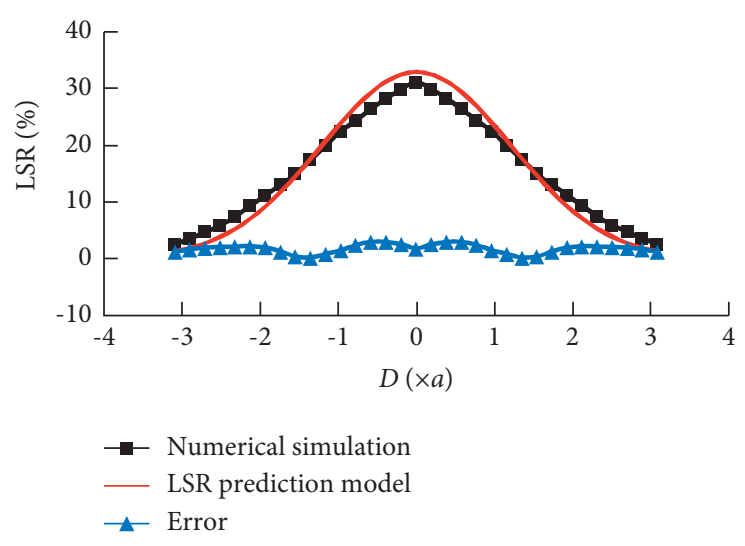

(b)

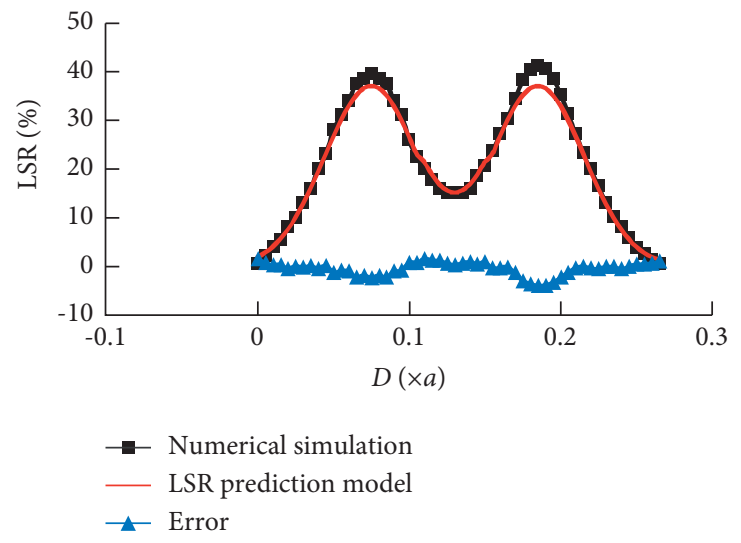

(c)

FIgURE 11: Error of the LSR prediction model. (a) Relative error of coefficients $A$ and $B$. (b) Absolute error of the LSR under a single wheelset. (c) Absolute error of the LSR under a bogie.

According to equations (4) and (6), equations (7a) and (7b) are transformed into functions represented by the actual levels as follows:

$$
\begin{aligned}
& A=2 \cdot 175+0 \cdot 041 a+0 \cdot 181 k_{f}-0 \cdot 076 a k_{f}+0 \cdot 0001 a^{2}+0 \cdot 018 k_{f}^{2}, R^{2}=0 \cdot 928, \\
& B=2 \cdot 399+0 \cdot 016 a-9 \cdot 174 k_{f}-0 \cdot 045 a k_{f}+0.0002 a^{2}+10 \cdot 123 k_{f}^{2}, R^{2}=0.863,
\end{aligned}
$$

where $k_{f}$ is the fastening stiffness in $\mathrm{MN} \cdot \mathrm{m}^{-1}$ and $a$ is the fastening spacing in $\mathrm{m}$.

Equations (1), (8a), and (8b) are the final LSR formulas. Through this group of functions, the LSR can be predicted from the fastening stiffness and the fastening spacing.

4.3. Error Analysis. The estimated values of coefficients $A$ and $B$ were compared with the calculated values, and the relative errors $\delta$ were calculated individually, as shown in Figure 11(a). The maximum prediction errors of coefficients $A$ and $B$ appear in the seventh and the sixth groups separately, and the errors are $5.72 \%$ and $5.21 \%$ individually, both less than $6 \%$. Hence, using equations ( $8 a$ ) and (8b) for prediction is reliable.

Under the sixth group of test parameters, the LSR curve was generated utilizing the prediction model composed of equations (1), (8a), and (8b). The LSRs obtained by the prediction model and numerical calculation are compared in Figure 11(b). The absolute error is always less than $3 \%$, which is acceptable.

The LSR curve under the excitation of a bogie was obtained by superimposing two LSR curves under the 
excitation of a single wheel. Figure 11(c) shows the curves of the prediction result, numerical result, and the absolute error. The prediction error is within 5\%, indicating that the prediction effect is satisfactory.

\section{Conclusions}

The load sharing ratio (LSR) is a significant factor for designing railway tracks, but current LSR formulas or calculation methods are too rough to satisfy the requirements, and the widely used "static loading method" for obtaining the LSR is inconsistent with reality.

This research has led to an improvement of conventional approaches in the calculation of the LSR by putting forward a new procedure of establishing multi-factor formulas of LSR under moving train excitation. Addressing the limitation of the "static loading method," a "moving loading method" was proposed to obtain the LSR under moving train excitation. On this basis, a procedure for establishing LSR multi-factor formulas was presented, containing the LSR fitting algorithm, parameter sensitivity analysis, and quadratic regression orthogonal tests. To investigate the performance of this procedure, a case study of Shijiazhuang Metro Line 1 was taken. The main conclusions of this article are as follows:

(1) When the axle is located directly above a fastening, the axle load is mainly borne by the surrounding five fastenings; when the wheel is located in the middle of adjacent fastenings, the axle load is primarily distributed by the surrounding six fastenings. The results of moving loading and static loading methods are almost the same, but the latter results are only part of the former.

(2) For the metro using the A-type vehicle and the monolithic trackbed, the fastening spacing and the fastening stiffness are the primary factors of the LSR function. At the same time, the fastening damping, the train speed, and the axle load have little influence, while the subsoil stiffness and the trackbed elastic modulus have almost no effect.

(3) For the metro using the A-type vehicle and the monolithic trackbed, the error between the LSR formulas and the vehicle-rail coupling simulation result is satisfactory.

For similar trains and track types, only one prediction model needs to be established according to the proposed method; then, the LSR prediction results can be obtained by adjusting the main parameters. Replacing current LSR calculation approaches with those recommended in this research will considerably improve the accuracy of the LSR prediction model.

It is worth noting that the LSR prediction model can only consider the influence of quantifiable factors, while nonquantitative factors (including train type and track type) need to be reflected by establishing a new LSR prediction model. For example, cars of type A, type B, or type $C$ may be used in metros, and passenger cars or freight cars may be used in railways. Track types include ballastless tracks and ballasted tracks, and track vibration reduction measures such as vibration damping fasteners may be adopted. The influence of different train and track types on the main parameters of LSR and the distribution of LSR requires to be further investigated in future research.

\section{Data Availability}

The data that support the findings of this study are available from the corresponding author upon reasonable request.

\section{Disclosure}

The opinions expressed in this paper are those of the authors.

\section{Conflicts of Interest}

The authors declare that there are no conflicts of interest regarding the publication of this paper.

\section{Acknowledgments}

This study was supported by the National Key R\&D Program of China (grant no. 2018YFC0808704) and Shijiazhuang Rail Transit Group Co. Ltd. (grant no. SJZM01B-ZGCSBGS005FW-2019). The authors are very grateful for the support. The authors also gratefully acknowledge Dr. Liu Wei for assistance in software operation and Prof. Wang Jianxi for suggestions on writing.

\section{References}

[1] J. Sadeghi, H. Liravi, and M. H. Esmaeili, "Experimental investigation on loading pattern of railway concrete slabs," Construction and Building Materials, vol. 153, pp. 481-495, 2017.

[2] S. Zhou, C. He, P. Guo, and F. Yu, "Dynamic response of a segmented tunnel in saturated soil using a 2.5-D FE-BE methodology," Soil Dynamics and Earthquake Engineering, vol. 120, pp. 386-397, 2019.

[3] D. P. Connolly, P. Galvín, B. Olivier, A. Romero, and G. Kouroussis, “A 2.A 2.5D time-frequency domain model for railway induced soil-building vibration due to railway defects," Soil Dynamics and Earthquake Engineering, vol. 120, pp. 332-344, 2019.

[4] Y. B. Yang, S. J. Liu, Q. M. Li, and P. B. Ge, "Stress waves in half-space due to moving train loads by $2.5 \mathrm{D}$ finite/infinite element approach," Soil Dynamics and Earthquake Engineering, vol. 125, Article ID 105714, 2019.

[5] Q. Jin, D. J. Thompson, D. E. J. Lurcock, M. G. R. Toward, and E. Ntotsios, "A 2.A 2.5D finite element and boundary element model for the ground vibration from trains in tunnels and validation using measurement data," Journal of Sound and Vibration, vol. 422, pp. 373-389, 2018.

[6] C. He, S. Zhou, P. Guo, H. Di, and X. Zhang, "Modelling of ground vibration from tunnels in a poroelastic half-space using a 2.5-D FE-BE formulation," Tunnelling and Underground Space Technology, vol. 82, pp. 211-221, 2018.

[7] P. Amado-Mendes, P. Alves Costa, L. M. C. Godinho, and P. Lopes, "2.5D MFS-FEM model for the prediction of 
vibrations due to underground railway traffic," Engineering Structures, vol. 104, pp. 141-154, 2015.

[8] A. Esveld, Modern Railway Track," MRT Productions, Delfi University of Technology, Delf, Netherlands, 2001.

[9] J. Sadeghi and A. Babaee, "Structural optimization of B70 railway prestressed concrete sleepers," Iranian Journal of Science and Technology Transaction B-Engineering, vol. 30, pp. 461-473, 2006.

[10] AREMA, Manual for Railway Engineering, American railway engineering and maintenance-of-way Association Publishing Service, Washington, DC,.USA, 2006.

[11] J. Eisenmann, Stress Distribution in the Permanent Way Due to Heavy Axle Loads and High Speeds, pp. 24-59, American Railway Engineering Association(AREA), WashingDon, DC, 1970.

[12] ORE, “The Dynamic Effects Due to Increasing Axle Loads from 20 to 22.5 Ton," Report D161-RP4, Office for Research and Experiments (ORE), International Union of Railways, Utrecht, the Netherlands., 1987.

[13] UIC, Technical Specification for the Supply Track Support and Classification of Line-Resulting Load Limit for Wagons, Union International des Chemics de Fer(UIC), Paris, France, 2004.

[14] N. Doyle, Railway Track Design, a Review of Current Practice, Australian Government Publishing Service, Canberra, Australia, 1980.

[15] C. O. Fredrick and S. G. Newton, "The relationship betweentraffic and track damage -The effect of vertical loads," British Broad Research and Development Division, London, UK, 1977.

[16] S. C. Saxena and S. P. Arora, A Text Book of Railway Engineering, Dhanpat Rai Publications (p) Ltd., New Delhi, India, 2004.

[17] R. D. Frohling, Measurement, Interpretation and Classification of South Africa Track Geometry, Swets and Zeitlinger Publisher, Prague, Czech Republic, 1995.

[18] C. W. Clark, Track Loading Fundamentals, The Railway Gazette, England, UK, 1957.

[19] J. Sadeghi and M. Yoldashkhan, "Investigation on the accuracy of current practices in analysis of railway track sleepers," International Journal of Civil Engineering, vol. 3, no. 1, pp. 34-51, 2005.

[20] D. L. Bartlett, "The stability of long welded rails," Civil engineering and public works review, vol. 55, no. 649, pp. 1099-1035, 1960.

[21] D. L. Heath, "Stresses beneath a railway track," Railway Gazette, vol. 124, pp. 1001-1006, 1966.

[22] O R M D, Critique of Conventional Track Design Procedures as Applied to Heavy Axle Load Conditions, BHP Melbourne Research Laboratories, Melbourne, Australia, 1978.

[23] AREA, Manual of Recommended Practice, American Railway Engineering Association, Washington D.C., USA., 1980.

[24] ORE, "Stresses in the Rails," Office for Research and Experiments (ORE), International Union of Railways, Utrecht, Netherlands, 1968.

[25] Z. C. Li, Study on the Vertical Load Transmision through the Track Structure and the Characteristics of Subgrade Dynamic Strsses, China Academy of Railway Sciences, Beijing, China, 2000, in Chinese.

[26] J. M. Sadeghi, "Experimental evaluation of accuracy of current practices in analysis and design of railway track sleepers," Canadian Journal of Civil Engineering, vol. 35, no. 9, pp. 881-893, 2008.

[27] H. G. Jiang, Dynamic Interaction of Slab Track StructureSubgrade System and Accumulative Settlement in High-Speed
Railways, Zhejiang University, Hangzhou, China, 2014, in Chinese.

[28] X. Bian, H. Jiang, Y. Chen, J. Jiang, and J. Han, “A full-scale physical model test apparatus for investigating the dynamic performance of the slab track system of a high-speed railway," Proceedings of the Institution of Mechanical Engineers - Part F: Journal of Rail and Rapid Transit, vol. 230, no. 2, pp. 554-571, 2014.

[29] Y. Zhou and J. Chen, "Research on the load transfer rule in ballastless track subgrade system of high - speed railway," Journal of Railway Engineering Society, vol. 33, no. 5, pp. 18-24, 2016, in Chinese.

[30] S. Tan, Z. Yu, Z. Shan, and J. Mao, "Influences of train speed and concrete Young's modulus on random responses of a 3D train-track-girder-pier coupled system investigated by using PEM," European Journal of Mechanics - A: Solids, vol. 74, pp. 297-316, 2019.

[31] D. Zhang, P. Xu, W. Zhai, and X. Zhang, "Long-term evolution mechanism of the rail weld irregularity in metro lines based on the wear theory," Wear, vol. 444-445, Article ID 203160, 2020.

[32] M. Oregui, Z. Li, and R. Dollevoet, "An investigation into the modeling of railway fastening," International Journal of Mechanical Sciences, vol. 92, pp. 1-11, 2015.

[33] Y. Q. Gong and Z. W. Zhang, "Formulation of Equivalent Stiffness for Semi-infinite Elastic Subgrade and its Application," Engineering Mechanics, vol. 24, no. 5, pp. 10-16, 2007, in Chinese.

[34] T. Jiang and H. Tajimi, Dynamic Soil-Structure Interaction Analysis Method: Principle and Application of Thin Layer Method, Tongji University Press, Shanghai, China, 2009, in Chinese.

[35] J. Piotrowski and W. Kik, "A simplified model of wheel/rail contact mechanics for non-Hertzian problems and its application in rail vehicle dynamic simulations," Vehicle System Dynamics, vol. 46, no. 1-2, pp. 27-48, 2008.

[36] Q. Xu, X. Ou, F. T. K. Au, P. Lou, and Z. Xiao, "Effects of track irregularities on environmental vibration caused by underground railway," European Journal of Mechanics - A: Solids, vol. 59, pp. 280-293, 2016.

[37] C. Zou, Y. Wang, P. Wang, and J. Guo, "Measurement of ground and nearby building vibration and noise induced by trains in a metro depot," The Science of the Total Environment, vol. 536, pp. 761-773, 2015.

[38] Z. Zhu, L. Wang, P. A. Costa, Y. Bai, and Z. Yu, “An efficient approach for prediction of subway train-induced ground vibrations considering random track unevenness," Journal of Sound and Vibration, vol. 455, pp. 359-379, 2019.

[39] Y. L. He, Z. W. Li, C. L. Sheng, and X. Chen, "Characteristic analysis of track spectrums of different subway line conditions," Journal of Railway Engineering Society, vol. 31, no. 7, pp. 99-104, 2014, in Chinese.

[40] F. Jin, H. Xiao, and X. H. Cui, "Study on track irregularity spectrum of fast urban rail transit line based on Burg method," Journal of the China Railway Society, vol. 42, no. 4, pp. 99-106, 2020, in Chinese.

[41] W. Lu, S. Ma, L. Gao, and X. B. Liu, "Analysis of track irregularity spectrum of the Beijing Subway lines," Journal of Railway Engineering Society, vol. 37, no. 3, pp. 101-106, 2020, in Chinese.

[42] Y. Sato, "Study on high frequency vibration in track operation with high-speed trains," Quarterly Reports, vol. 18, no. 3, pp. 22-27, 1977. 